\title{
Estratégias de enfrentamento do câncer de mama: um estudo de caso com famílias de mulheres mastectomizadas
}

\author{
Coping with breast cancer: \\ a case study on families of mastectomized women
}

Jeane Saskya Campos Tavares ${ }^{1}$

Leny Alves Bomfim Trad ${ }^{2}$

${ }^{1}$ Centro de Ciência da Saúde, UniversidadeFederal do Recôncavo da Bahia. Rua do Cajueiro s/n, Cajueiro. 44574-490 Santo Antônio dejesus BA.

jeanesctavares@gmail.com

${ }^{2}$ Instituto deSaúde

Coletiva, Pró-Reitoria de

Pesquisa e Pós-Graduação,

UniversidadeFederal da

Bahia.
Abstract This study sought to analyze strategies for coping with the disease and the implications of breast cancer for the affected families. Semistructured interviews and observations were conducted in households with 5 families of women diagnosed with breast cancer in various stages of development and care, which were treated in a hospital specialized in Oncology. 21 people had been interviewed: 5 patientsand 16 familiar members. The categories investigated were: Search for information, direct action, inhibition of action, intrapsychic efforts, back up to the other. Findings show a disparity between strategies adopted by patients and family members. The process of coping with cancer emphasized the dialectical relationship between patients and relatives, the active and constant participation by members of the families of origin, relations and friends, the characteristics of the institution where women with breast cancer were treated and the implications of this type of cancer.

Key words Breast cancer, Family, Coping process, M astectomy
Resumo Este estudo pretendeu conhecer eanalisar estratégias de enfrentamento do câncer de mama desenvolvidas por famílias que têm entre seus membros mulheres com esta doença. Foram realizadas entrevistas semiestruturadas e observações em residências de cinco famílias de mulheres com diagnóstico de câncer de mama, totalizando 21 entrevistados, em diferentes estágios da doença e tratamento num hospital especializado em oncologia. Foram investigadas estratégias das categorias: busca de informação, ação direta, inibição de ação, esforços intrapsíquicos, voltar-se para os outros. Destacaram-se no processo de enfrentamento do câncer a relação dialética entreas estratégias de pacientes e familiares, a participação ativa e constante dos membros das famílias de origem e extensa e as características da instituição em que as mulheres com câncer de mama foram atendidas.

Palavras-chave Câncer de mama, Família, Enfrentamento - processos, M astectomia 
Introdução

0 câncer de mama permanece como o segundo tipo de câncer mais frequente no mundo e o primeiro entre as mulheres ${ }^{1}$. No Brasil, é o câncer mais comum e principal causa de morte entre as mulheres, além de ter sido o mais frequente neste país na década de noventa 2 . 0 aumento da incidência eda mortalidadeéatribuído à melhoria da precisão diagnóstica e da qualidade do preenchimento das declarações de óbitos. Contudo, mantêm-se como causas principais o diagnóstico e tratamento tardios. Além disso, há impossibilidadede prevenção primária total, pois sua etiologia envolve fatores de risco associados à vida re produtiva da mulher e características genéticas ${ }^{1}$.

Para compreensão ampla deste problema, devem-se considerar, além da dimensão biológica e epidemiológica, a psicossocial. Receber o diagnóstico de câncer éum evento potencialmente desestruturador para o paciente e sua família, pois a enfermi dade não se reduz à dimensão física e à percepção sensorial de mal-estar daquele queadoece. Trata-se da experiência sociocultural da doença, que é construída a partir da interação entre os indivíduos e suas instituições ${ }^{3}$.

Conforme o modelo transacional de enfrentamento, a habilidade e recursos dos familiares para lidar com fatores potenciais de estresse são mediadores dos níveis de sofrimento e bem-estar psicológico dos envolvidos em uma enfermidade grave. No caso específico do câncer, as estratégias de enfrentamento adotadas e/ou desenvolvidas pel os familiares repercutem sobreo tempo desobrevida da pacientee, por fim, recuperação do grupo familiar após a fase crônica da doença ou morte da paciente ${ }^{4}$.

Este estudo teve como objetivos analisar as principais estratégias de enfrentamento adotadas por famílias de mulheres com câncer de mama. Especificamente buscou-se descrever as estratégias de enfrentamento desenvolvidas por estas famílias para lidar com o adoecimento e tratamento e, por fim, discutir as repercussões da adoção de diferentes categorias de estratégias sobre o cotidiano e relações familiares.

0 foco na família levou em conta os seguintes aspectos: (a) o papel fundamental da família como rededesuporte social, compreen dida como espaço estratégico para investigação do processo de enfrentamento do câncer; (b) os riscos à saúde aos quais os familiares são expostos ao longo do processo de tratamento do câncer e (c) 0 incremento de pesquisas científicas que tomem os comportamentos do grupo familiar como obje- to deestudo, entendendo a família enquanto contexto privilegiado para a observação de práticas e significados associados à doença ${ }^{5}$. Vale ressaltar que o estudo com famílias de pacientes adultos com câncer de mama e o olhar sobre o contexto doméstico são ainda escassos na produção brasileira. A maioria dos estudos é realizada com famílias de crianças internadas em hospitais.

\section{Família, cuidados e estresse}

A família destaca-se como principal rede de suporte social do doente nas diferentes fases do tratamento. A pós o diagnóstico, os familiares priorizam a sobrevivência do enfermo, tendem à união e reorganização do grupo para atender necessidades imediatas, sintomas e sistema mé dico ${ }^{6}$. Em seguida, na fase crônica, os familiares preocupam-se com as habilidades necessárias para tolerar os tratamentos prescritos, questões econômicas e com a reintegração social da muIher quando mastectomizada ${ }^{7}$. Na fase terminal, há clareza quanto à inevitabilidade da morte, as atenções estão voltadas para os cuidados paliativos ereal ização do luto antecipatório ${ }^{8}$. N estafase, a família manifesta maior necessidade de controle da ansi edade, enquanto o paciente concentra-se no controle dos sintomas4.

A participação familiar pode contribuir para que a paciente lide melhor com o estresse associado aos tratamentos como quimioterapia e mastectomia, cujas implicações estéticas podem gerar sérias alterações na autoimagem das mulheres e na sexualidade dos casais. São relevantes, ainda, as questões de gênero relacionadas à mudança de papéis familiares e, por fim, significados e modos de enfrentamento femininos baseados na longa história de dor, vergonha e medo que acompanha esta doen ça9,10.

De modo geral, espera-se que a família desempenhediferentes papéis e executetarefas complexas que envolvem prover suporte emocional, compartilhar responsabilidades de tomada de decisão e comunicação com profissionais de saúde, principalmente quando o doenteestá debilitado. Além disso, devem prestar cuidados desaúde, arcar com altos custos financeiros e sociais e ainda preencher o papel e a contribuição do membro enfermo para restabelecer a estabilidade do grupo ${ }^{11}$.

Estas são tar efas potencialmente estressantes relacionadas às complexas demandas e constante necessidade de adaptação gerada pela evolução e tratamento do câncer, configurando-se 
num período crítico para a saúde do grupo ${ }^{12-16}$. $\mathrm{N}$ a maioria dos casos, a necessidade de lidar com estas demandas tornam as famílias dos doentes uma segunda ordem de doentes com câncer ${ }^{11}$ ou "doentes ocultos"17. 0 estresse crônico e as respostas a ele podem afetar o sistema nervoso simpático, alterando o sistema endócrino e imunológico e deixando o organismo dos indivíduos altamentevulnerável a problemas de saúde como o próprio câncer e doenças infecciosas ${ }^{18,19}$.

Aliada à mudança imunológica mal-adaptada, observa-semaior presença de comportamentos de risco à saúde entre familiares de pessoas gravemente enfermas, como aumento de ingestão de bebidas alcoólicas, fumo e acidentes nos períodos de elevado estresse ${ }^{20}$. E, em relação aos doentes com câncer, são identificados altos níveis de desordens psiquiátricas nos familiares próximos, sendo que a severidade de depressão eansiedade é maior entre familiares que nos próprios doentes ${ }^{21}$.

No entanto, é importante ressaltar que cuidar de uma mulher com câncer é uma situação apenas potencialmente estressante. 0 comprometimento da saúde psíquica efísica dos envolvidos nos cuidados com as pacientes, além das mudanças estruturais e dinâmicas no grupo familiar, está diretamente relacionado às suas estratégias de enfrentamento.

\section{O model o transacional de enfrentamento}

Para análise destas estratégias, neste estudo utilizou-se o modelo transacional proposto por Lazarus e Folkman ${ }^{22}$, que caracteriza o enfrentamento (coping) como um processo constanteque envolve mudanças cognitivas e comportamentais, no qual os indivíduos lidam com as exigências (internas ou externas) avaliadas como estressantes em sua relação ao ambiente ${ }^{23-26}$. A pós avaliação inicial do evento como estressante, são desenvolvidas estratégias, comportamentos manifestos ou não, que têm como objetivos minimizar a ação das condições ambientais que causam dano e perdas ao indivíduo e, simultaneamente, aumentar a sua possibilidade de recuperação e bem-estar.

Todo este processo é mediado por fatores de enfrentamento relacionados aos aspectos médi$\cos$, socioculturais e individuais ${ }^{11}$. Os aspectos médicos englobam os fatos clínicos, tipo e curso do tratamento proposto, opções de reabilitação e manejo psicológico pela equipe de cuidados de saúde. Os aspectos socioculturais dizem respeito aos recursos disponíveis, às atitudes, estigma e significados relacionados ao câncer desenvolvidos na comunidade, natureza e acesso a suporte social (família, amigos, grupos afiliados). As variáveis pessoais estão relacionadas ao paciente, como o momento do ciclo vital em que seencontra (tarefas específicas do desenvol vimento ameaçadas ou interrompidas pelo câncer), a sofisticação das habilidades pessoais, a capacidade cognitiva para lidar com situações de al to estresse, o seu locus de controle, a experiência de enfrentamento prévia com outras doenças ou com o próprio câncer, os valores morais, religiosos e crenças.

As estratégias de enfrentamento desenvolvidas pela paciente e seus familiares estão, portanto, diretamente relacionadas à prevenção e ao sucesso do tratamento do câncer. Materializamseem comportamentos como, por exemplo, busca por informações e atenção médica preventiva, assim como a adesão da família e pacientes aos tratamentos medicamentosos e psicoterápicos indicados. Dizem respeito, ainda, à qualidade do processo de decisão sobre a mastectomia, à capacidade de entendimento e execução de procedimentos relacionados ao cuidado, ao acionamento e participação em redes de suporte social, influenciando a qualidade de vida de pacientes e familiares ${ }^{14,27,28}$.

\section{M etodologia}

As pesquisas nacionais e internacionais sobre 0 fenômeno do enfrentamento/adaptação psicológica dos indivíduos têm priorizado métodos quantitativos. No entanto, estes métodos são considerados inadequados para a apreensão de aspectos subjetivos inerentes à esta problemática29. O ptamos pelo método qualitativo, visando identificar como os sujeitos constroem a experiência de adoecer e como mobilizam forças para recuperação da saúde ${ }^{30}$ através do estudo de caso.

\section{Participantes}

Participaram famílias de pacientes atendidos no Hospital Aristides M altez (H AM ), uma instituição filantrópica, centro de referência em assistência médica, pesquisa e ensino em oncologia, localizada na cidade de Salvador (BA). Procurouseincluir pacientes com diferentes perfis deevolução, tempo de doença, estrutura familiar efuncionamento social. A categoria família foi definida como grupo social, cujos membros mantêm um sistema de relações significativas entresi ${ }^{31}$, do qual 
a paciente com câncer de mama é um dos membros. Portanto, familiares eram aqueles referidos pela paciente como tal, indicando vínculo biológico, afetivo ou de conjugalidade com a mesma, independente deexistir vínculo jurídico.

As cinco famílias (identificadas pelas iniciais dos nomes fictícios dos participantes A, C, E, I, e S) selecionadas para o estudo tinham entre seus membros uma mulher que havia recebido diagnóstico de câncer demama eque esteve ou estava em diferentes fases detratamento no hospital. Ao todo, foram entrevistadas 21 pessoas, sendo cinco pacientes e dezesseis familiares. A idade das pacientes variou entre 46 e 52 anos, em sua maioria estavam casadas há mais de vinte anos e tinham dois ou três filhos. Exceto no caso da família A, os filhos das pacientes estavam na fase da adolescência ou eram adultos jovens na época do recebimento do diagnóstico de câncer de mama.

\section{Procedimento}

Foram cumpridas todas as determinações da Resolução n 196/96 (CNS) sobre pesquisa com seres humanos e o estudo foi aprovado pelo Comitê de Ética em Pesquisa (CEP) do HAM. Após esta aprovação, deu-se início à identificação de possíveis participantes, que se deu através de consultas em prontuários, aos profissionais do serviço de psicologia da instituição, apresentação da pesquisa nos grupos de atendimento às famílias de pacientes na fase terminal da doença e de mulheres mastectomizadas, além de indicações das próprias pacientes.

As primeiras entrevistas semiestruturadas foram realizadas na própria instituição, respeitando as normas e rotinas dos atendimentos médicos e psicológicos oferecidos aos pacientese familiares. A pós o consentimento das pacientes, procedeu-se à observação nos domicílios acompanhada das entrevistas individuais e/ ou grupais, de acordo com a disponibilidade das famílias.

Foram utilizados como instrumentos: (a) ficha de consulta aos prontuários médicos - para coleta sistemática das informações clínicas relevantes; b) roteiro de entrevista semiestruturada - enfocando histórico de experiências anteriores com outras doenças e com o câncer, modelos explicativos desenvolvidos sobre 0 câncer, formas de tratamento, alterações da rotina familiar e emoções experimentadas após o diagnóstico de câncer, estratégias adotadas para lidar com 0 diagnóstico/tratamento do câncer, expectativas quanto ao tratamento, planos eavaliação do gru- po sobre seu futuro; (c) genograma focalizado na doença - visou traçar a genealogia familiar, procurando identificar, como sugere M cDaniel ${ }^{6}$, a identificação de eventos disruptivos associados ao adoecimento na família e a apreensão de mitos e padrões familiares relativos ao processo saúde-doença; (d) linha de tempo familiar - disposição cronológica dos principais fatos relacionados à saúde na história de cada família. As categorias família de origem ou família de procriação referem-se às famílias elementares das quais uma pessoa pode participar simultaneamente ${ }^{32}$ : família de origem ou de orientação, enquanto filho e irmão (ou filha e irmã), e família de procriação ou de reorientação, como marido e pai (ou esposa e mãe).

\section{Análise de dados}

A análise do conteúdo das entrevistas e do genograma orientou-se pelas três categorias principais do estudo: alterações biopsicossociais associadas ao câncer pelas famílias, estratégias de enfrentamento e fatores de enfrentamento que mediaram o processo, considerando os sentidos compartilhados entre gerações (genograma). Utilizou-se como ferramenta complementar o programa QSR.N UDIST - Vivo (Qualitative Solutions\& Research-Nonnumerical, Unstructured Data), que permite a sistematização e gerenciamento de dados etnográficos, sendo de responsabilidade do(s) pesquisador(es) a criação e interpretação das categorias analíticas.

\section{Resultadosediscussão}

Principais estratégias desenvolvidas

As estratégias adotadas pelas pacientes e por seus familiares nos cinco núcleos analisados revelam-se diversas e, por vezes, contrastantes. A maioria dos familiares tende a omitir ações que considerem perigosas para a paciente e empenham-se em negar o câncer. Vale ressaltar que esta tendência diz respeito aos integrantes da família de procriação das pacientes, portanto, a maioria dos entrevistados. Os membros das famílias de origem, por sua vez, parecem incentivar e concordar com as estratégias das pacientes.

As pacientestendem a assumir atitudes ecomportamentos que efetivamente possam resolver seus problemas. Baseando-se na proposta de Cohen e Lazarus apresentada por Gimenes ${ }^{30}$, para esta análise, foram utilizadas as seguintes catego- 
rias de estratégias: (a) busca de informação - re ferindo-se às informações relevantes para a resolução de problemas e/ou regulação de emoções; (b) ação direta - conjunto de atitudes e comportamentos assumidos pel os sujeitos a fim de resolver os problemas gerados pelo câncer; (c) inibição de ação - refere-se à contenção de ações e atitudes impulsivas ou consideradas perigosas pelos sujeitos; (d) esforços intrapsíquicos - esforços que permitem aos sujeitos negar, esquivar-se do problema, intelectualizá-lo, a fim de regular suas emoções diante da ameaça da doença e (e) voltar-se para os outros - reconhecimento da importância do apoio social ebusca deste tipo de apoio para lidar com o câncer.

Entre as pacientes entrevistadas, as principais estratégias observadas foram à busca de informações sobre o câncer demama e deapoio ou de suporte social na família de origem ou junto a outras pacientes, bem como a procura imediata por assistência médica especializada (ação direta); esta última, referida por todas as pacientes.

H ouve uma única referência à associação entre o tratamento médico formal à medicina "alternativa". Foi utilizada como tratamento adjuvante a ingestão de "garrafadas de babosa" que Senão fez bem, mal também não fez. Graçasa D eus nesse período [da quimioterapia] todo dia que eu fazia meus exames estavam ótimos. Eu acredito ainda em remédio casei ro [risos], a crença popular. (Elma, 52 anos, paciente)

A busca por suporte espiritual também foi relatada, pelas pacientes e por diversos familiares. 0 suporte espiritual influenciou, por exemplo, a adesão aos tratamentos: Eu busquei ajuda no centro espírita. A resposta que os espíritos deu foi que eu pudessefazer a cirurgia queia tudo ocorrer bem eque o meu caso não era de espiritual, era médico da terra. Eu fiz, graças a Deus. (Elma)

Para vários participantes, a fé dá força para ultrapassar os obstáculos e conforto através da manutenção da esperança, além de auxiliar na promoção do bem-estar do grupo, dando a sensação de segurança: Nós somos muito católicos. Dentro do catolicismo, me dá uma força muito grande, um apoio muito grande, o religioso, a minha mãeéaltamentecatólica, asminhas tias. $\mathrm{N}$ ada neste mundo é por acaso e como existe um Deus Todo Poderoso, ele podefazer milagres, então énesse milagre que a gente acredita. Eu tenho certeza que Deus dará bom destino a ela [chora]. (Angélica, 34 anos, irmã)

Nós passamos por isso, mas de uma forma até segura, até serena, eu não sei se porque. Aceito um pouco o lado da espiritualidadeea gentesabe quea gente tá aqui e tudo o que a gente passa tem um porquê, tem um para que. (Elaine, 31 anos, filha)

Olha, eu fui pra o espiritismo, meu cunhado é espírita, fiz cirurgias espíritas, como eles mandavam fazer eu fazia, tem uma tia minha que é da messiânica, não é mãezinha? Vinha aqui me dar johrei eu acho que todas as religiões, todos os tipos quequeiram rezar pra mim, orar para mim éuma forma muito grande de me dar uma atenção certo? (Alana, 37 anos, paciente)

O suporte espiritual parece estar também relacionado à aceitação da doença e aos significados do câncer construídos nestes grupos, uma vez que estes se associam às noções de adequação emerecimento para desenvolver a doença. $\mathrm{A}$ estratégia "aceitar a doença", que pode se confundir com "racionalizar a doença", é a apontada tanto por pacientes quanto por familiares como uma forma eficiente de lidar com o câncer. Há uma tendência em considerar que a "revolta" implica a não-sobrevivência ao câncer: Cada paciente age de um jeito, não aceita, se desespera, quer morrer, quer fazer e acontecer, se achando a pior pessoa do mundo. Eu acho que a melhor coisa que o paciente pode fazer é aceitar. Porque se você aceita, vocêfaz seu tratamento numa boa, não faz com raiva, não faz contrariada, não xinga. N ão se desespera porque tudo isso eu acho que vai bulir no seu emocional, né? (Elma, 52 anos, paciente)

Quando eu cuidava de minha mãe, eu pensava na doença ea doença veio para mim. Eu mepreparo para aceitação, eu me preparo para a reação positiva da coisa, para que eu viva mais tempo. (Izadora, 49 anos, paciente)

0 câncer apresenta-se nos depoimentos de todos os entrevistados como uma doença que só podeser superada através da parcimônia. A maior parte das estratégias adotadas nas famílias inclui-se nas categorias inibição de ação e esforços intrapsíquicos. Em relação à primeira categoria, os familiares evitavam falar sobre morte diante da paciente, conversar sobre a doença principalmentecom ela, demonstração de desânimo ecansaço pelos cuidados prestados, falar sobre encargos financeiros, externalizar emoções e desejosconsiderados prejudiciais para a paciente, discutir ou discordar da mesma e participar de atividades relacionadas à doença, principalmente 0 acompanhamento da paciente ao hospital.

As estratégias de inibição de ação foram mais enfatizadas pelosmaridos das pacientes. N enhum dos cônjuges ouvidos afirmou acompanhar a paciente para atendimento médico ou realização de exames e, exceto André, todos evitavam discussões com a paciente para protegê-la: [suspi- 
ra] Tem hora que ela mediz um bocado de coisa, e eu já disse a ela: "olha, eu só ouço essas babosei ras porque é você, se é outra pessoa eu não ouço não". $M$ as dela eu ouço porque a gente tem que ter um cuidadinho com ela, né? (Ivan, 59 anos, marido)

Tentar agir como se não houvesse problemas na relação familiar, com o intuito de poupar a paciente, é reconhecido por Carlos (54 anos, marido) como uma forma deenfrentamento que utiliza contra sua vontade. Esta estratégia, na sua interpretação, o protege contra novas acusações familiares de ser 0 causador da doença de Célia (54 anos, paciente), enquanto não se separa de sua família.

M ostrando-se angustiado e depressivo, Elson ( 63 anos, marido), pareceu, segundo a família Esperança, não ter condições emocionais de lidar com a possibilidade da morte de Elma: De todos eu acho que quem mais sentiu foi meu pai, porque [fala baixo e pausadamente] ele é muito ligado a ela, então da primeira doença ele sentiu, quando veio essa logo depois ele sentiu mais ainda, então eu acho que quem ficou [ênfase] abalado foi ele e a mãe dela. (Elaine, 31 anos, filha)

Elson afirma ter sido informado sobre o diagnóstico e cirurgia de Elma somente após a real ização da mesma; no entanto, manteve-se próximo de Elma, sempre que possível, durante 0 período de recuperação da mastectomia. Segundo a família Esperança, por não gostar de médicose de hospitais, inicialmente eleevitava buscar informações sobre o estado de Elma por receio de "saber demais" e não a visitou durante o período de internação.

A participação pouco efetiva de Elson deveuse, para os familiares, à rapidez com que Elma recebeu alta médica (dois dias) eà inabilidadede Elson em lidar com o sistema médico. Entretanto, Elson aponta como principal causa do seu comportamento o medo de "contaminar" Elma com sua depressão pela falta de emprego.

N outro sentido, 0 afastamento físico e afetivo de André diante das recidivas do câncer em Alana é considerado uma das causas de depressão e agravamento do quadro da paciente: A última quimioterapia que eu fui fazer ele se negou a melevar pro hospital. E eu não tinha ninguém que me levasse. Então meu irmão teve que deixar 0 trabalho pra ir me pegar pra melevar porque elese negava terminantementedemelevar pra fazer uma quimioterapia. (Alana)
Relação entre estratégias:

conflitos e sofrimento

As diferenças nas percepções entre os cônjuges de como enfrentar o adoecimento parecem contribuir para a elevação da tensão familiar. 0 choque entre as estratégias adotadas, no caso de Alana e André, para a manutenção da normalidade, respectivamente "aceitação da doença" e "manifestação de agressividade e negação", gerou mais estresse. N este sentido, a ansiedade eos frequentes conflitos podem estar associados também aos enfartes sofridos por Andréneste período: Ele me gritava e eu no momento que ele me gritava eu merecuava que eu não gostava debriga. Então isso aí foi eu mecalando e ele se posicionando como onipotente, né? Ele teve um enfarto, certo? Então desestruturou tudo. Só que eu dentro da minha doença, eu procurava fazer com que a família se tornasse uma família normal, sem muita coisa, aceitar a doença e partir pra vida normal até a hora que Deus dissesse "Não, tá na hora da gente ir embora. (Alana)

Este tipo de estratégia adotada pela maioria dos familiares produz a sensação de abandono nas pacientes e a sobrecarga dos cuidadores, que têm seu trabalho dificultado pela comunicação deficiente no grupo. No caso de Izadora, o distanciamento ea indiferença percebidos na família de procriação são exemplificados pela falta de companhia durantea realização dos exames: Pelo fato de eu vir sozinha, eu vejo tanta gente acompanhada, aí eu acho que sou diferente. [Gostaria] que sentissem mais a coisa, mesmo que pra o próprio bem deles. Eles acompanhando a mim, eles podiam, elas inclusi ve que são mulheres estão propícias a terem também um carcinoma de mama, uterino que minha família tem essa tendência. $E$ isso talvez bula um pouco assim comigo e quando eu vou falar elas, elas não gostam. (Izadora)

No entanto, apesar do desconforto, Izadora aponta benefícios da negação do seu estado clínico por seus familiares: Talvez se eles sentissem e ficassem falando que eu sou doente, aí a coisa ia ficar sempre na minha lembrança, talvez isso fizesse mal a mim, agora tem momentos queeu acho que a indiferença chega atéa pesar um pouco, né? Eu atél louvo a hora que el as fazem assi $m$. Querendo que o respei to fosse porque eu sou Izadora, sou a mãe delas, não porque eu seja doente. (Izadora)

Esforços intrapsíquicos foram citados com frequência entre os familiares: animar a paciente e outros familiares para não ficar deprimidos, incentivar a obediência das recomendações mé dicas, não pensar na doença ou na possibilidade 
de também adoecer por câncer, negar o estado clínico da paciente, não se preocupar com o câncer e suas repercussões. De maneira geral, tentase "esquecer" ou "pensar em coisas boas" para evitar refletir sobre 0 adoecimento por câncer.

$\mathrm{N}$ egando o estado clínico da paciente, familiares podem exigir que as pacientes mantenham suas atividades normais, garantindo o bem-estar do grupo: [André exigia que] eu com quimioterapia, eu entrasse numa sala de aula e fosse dar aula. E ai de mim que não desse, sabe? Depois ele me põe pra fora, bota a recepcionista no meu lugar como se eu não fosse nada [ênfase] ali dentro. Era tanta poeira que eu tava tomando quimioterapia, o médico sentiu uma secreção no meu pulmão e era exatamente essa poeira. (Alana)

Apesar de gerar "dor na consciência", manter os padrões de relacionamento conflituoso com a mãe, anteriores ao câncer, permite que Í sis naturalize a doença, pois o câncer, uma vez não reconhecido, está intelectualmente controlado: Eu nunca gostei de tratar uma pessoa como coitado assim, sabe? Por exemplo, se eu tô com vontade de brigar naquela hora, não vou brigar por teve câncer entendeu? Eu posso não brigar porque tá errado uma filha brigar com a mãe, masnão por causa disso. Eles botam muito assim "ah, coitada de sua mãe", eu não vejo isso. [O sfamiliares diziam] "não pode fazer isso, não pode fazer aquilo". Não tem nada a ver uma pessoa não poder lavar um prato, bota uma luva. (Ísis, 18 anos, filha)

Uma crença recorrente entre as famílias é de quenão se deve pensar no câncer para não "atraíIo". Como afirma Sílvio (17 anos, filho): Quando pensa, dizem que atrai né? Então eu costumo não pensar, mas é a vida, né? Veio. Se um teve, outro teve, 0 outro pode ter pode não ter também, então eu penso em não ter, mas se tiver paciência né? A gente vai ter que levar, empurrar com a barriga e seguir em frente.

A principal, emais perigosa, consequência da utilização desta estratégia é que ela representa a opção por não prevenir o câncer exatamentepelo grupo formado por pessoas com alto risco gené tico para o desenvolvimento da doença: os filhos das pacientes. Por temer o desenvolvimento do câncer de mama decorrente da preocupação demasiada com esta possibilidade, Elaine passou a evitar o contato com a doença, através do distanciamento de outros pacientes, evitando olhar para a cicatriz da mastectomia no período de re cuperação de Elma e não realizando periodicamente 0 autoexame: Falo "ah, não vou ficar encucando com isso não, que se eu ficar encucando aí éque realmentevai aparecer". Sealguma coisa está medoendo eu faço tudo pra esquecer a dor eeu sigo adiante. Não faço tratamento nenhum. De vez em quando éque eu faço 0 autoexame, mas não fiquei naquela paranóia do começo. Eu senti tudo como se fosse uma paranóia. Agora não encaro mais assim. (Elaine)

O comportamento da filha caçula de Izadora é um exemplo do quanto a combinação destas estratégias pode gerar sofrimento de toda família e aumentar o risco para o surgimento de novos casos no grupo. Ísis evita pensar sobre o câncer e não conversa sobre seus temores com outras pessoas: Ah, foi chato, foi chato pra caramba, eu era menor. Eu nunca me liguei em coisa de doença, eu odeio hospital, odeio visitar gente em hospital. O deio cemitério, odeio tudo isso, então eu me desligo. Eu não procuro me inteirar de nada assim. Eu não gosto de falar de doença de hospital de morte disso, nunca gostei. (Ísis)

Destaforma, Ísis procura não ter contato com a doença ou qualquer coisa relacionada a ela (morte, vista em hospital, cemitério). Por isso, evita se inteirar sobre estado da mãe, não busca informações sobre o câncer e não se envolveu nos cuidados das outras familiares que tiveram câncer de mama. Sente-se angustiada por não ter cuidado de sua mãe e por não a ter visitado no hospital, mas justifica esta forma de agir por considerar esta situação insuportável: Eu procuro me desligar [chora]. Ela ficou muito chateada comigo agora porque eu não fui visitar ela porque ela fez o negócio, maséqueeu não gosto de hospital [continua chorando]. Assim quando eu vou me sinto mal ao ver aquele povo todo doente, eu sinto um enjôo, sinto o cheiro e tudo me incomoda entende? Aí eu não vou. (Ísis)

Sua forma de enfrentar a doença, motivada principalmente pelo medo de também desenvolvê-la, gerou conflitos familiares, desconforto emocional, além de impossibilitá-la de adotar comportamentos preventivos. Ísis vive numa situação paradoxal, pois se vê diante da necessidade de cuidar da mãee, ao mesmo tempo, de não a reconhecer enquanto ser doente, nem a si mesma como parte de um grupo de risco.

Embora menos enfatizadas nos relatos, mas não menos prejudiciais, foram referidas pelas pacientes estratégias que se enquadram nas categorias inibição de ação e esforços intrapsíquicos. A fim de "não preocupar" os familiares, algumas pacientes optam pelo silêncio em relação ao seu sofrimento e se esforçam por aceitar a doença, minimizando suas repercussões. É o caso de Sônia, cujos filhos não puderam acompanhar o seu processo de adoecimento, em função do silêncio 
que ela adotou em relação ao câncer que contraíra. Sérgio e Sílvio, filhos de Sônia, deduziram o que estava acontecendo com a mãe através da escuta de conversas desta com vizinhas e amigas. Em seus depoimentos, mostraram pouca compreensão sobre o que era o câncer e sobre os tratamentos realizados por sua mãe, fato que se reve lou gerador de angústias e incertezas para ambos.

A confirmação do câncer ocorreu, defato, no momento em que Sônia regressa à casa, depois de submeter-se a mastectomia. Além de escutar os relatos da mãe sobre a cirurgia, Sérgio eSílvio constatam que esta perdeu uma mama.

No caso de Alana, a intenção era evitar fazer "escândalo" com a doença e incrementar o medo diante dela. Assim sendo, demonstrava otimismo, evitava lamúrias e reclamações: Ela [Angélica] quase cai, aí chorou, eu digo "calma, não é por aí, não se desespere, o diabo não étão feio", sabe? E dando tranquilidade o máximo que eu pude porque eu sempre sou assim, eu procuro não fazer o bicho de sete cabeças. E aí eu comecei a ver que realmente não era tão feio assim, fazer uma cirurgia etudo, tudo bem, só que o meu caso complicou. (Alana)

As estratégias de enfrentamento das categorias inibição de ação e esforços intrapsíquicos utilizadas pelas pacientes são consideradas fundamentais para a avaliação familiar sobre seu estado. Exceto a família $C$, todas as famílias afirmaram que, apesar do sofrimento com o tratamento e suas repercussões, as pacientes estavam "bem": M inha mãe foi fazer a cirurgia mas, minha mãenão passou fragilidade, sabe? Seficou abalada emocionalmente, ela não passou pra gente. Por ela já ver a historia anterior de outros familiares dela, ela sedecidiu efoi bem firme. (Ingrid, 20 anos, filha)

Ela mesma fez o trabalho de psicologia com gente. Que não se preocupasse que ela tava bem. Eu acho que você se preocupa mais quando você vê uma pessoa quetá arrasada, largada, você fica preocupada como levantar e ela não, ela já estava no alto. Ela que levantava a gente. (Elisa, 25 anos, filha)

Logo depois que ela perdeu a mama, aí apare ceu uma mulher na televisão falando que fez isso. Falou até um negocio engraçado: "o que tá ruim é bom tirar logo ejogar fora" Aí ela ficou atéfalando isso também. Aí depois a gente: "é, se tá bom pra senhora, tá bom pra gente né?" (Sílvio, 17 anos, filho)

A família A foi a única a expressar sua percepção do esforço da paciente em poupá-los do sofrimento: Ela vai enganando, pensando que está enganando as pessoas [sorri olhando para Alana]. Ela não se queixa, ela não fala. M inha filha, Alana é muito alegre, então isso fortalecea pessoa, porquese a gente visse triste, acabrunhada, o sofrimento ia ser maior. Então a gentetem que agradecer dela ser o que ela é, alegre e feliz que não se queixa de nada. (Antônia, 70 anos, mãe)

É importante salientar que estas categorias aparentemente indicam o uso de estratégias apenas paliativas e, portanto, pouco eficazes e por vezes nocivas, como, por exemplo, manter a esperança. No entanto, também é relativa esta avaliação a priori sobre a efetividade destas estratégias, pois é necessário considerar o momento em que este tipo de estratégia está sen do utilizado ea natureza do estressor.

\section{Consideraçõesfinais}

Concordando com a literatura, o estudo constatou que as famílias constituem importantes fontes de cuidados primários e suporte social das pacientes afetadas pelo câncer de mama. No que diz respeito às principais estratégias de enfrentamento adotadas pelos participantes, foram observadas diferen ças rel evantes entre as categorias de estratégias utilizadas por pacientes e os integrantes de sua família de origem e de procriação. Enquanto as pacientes e os integrantes do primeiro grupo tenderam a voltar-se para a resolução de seus problemas, os membros das famílias atuais buscaram concentrar-se na inibição de ações e pensamentos considerados prejudiciais.

Como aponta Nascimento-Schulze ${ }^{33}$, a adoção de estratégias de enfrentamento adequadas é um dos fatores que contribuem para a qualidade de vida de pacientes e familiares. Neste sentido, é preocupante a postura de negar o câncer, observada em al guns familiares de mulheres afetadas por esta enfermidade, uma estratégia que pode inibir a adoção pela família de condutas que visem prevenir o surgimento de novos casos de câncer entre seus membros. Esta situação revela-se ainda mais preocupante se considerarmos o fato de que a postura referida foi constada entre os filhos de pacientes, os quais integram os grupos de el evado risco genético para o desenvolvimento da doença.

O sofrimento, instância subjetiva que ameaça a uni dade e integridade da pesso $a^{30}$, foi identificado como principal responsável por inibir ou comprometer a participação dos familiares em atividades sociais e produtivas. Particularmente, foi identificada entre as possíveis causas deste 
sofrimento a convivência com a incerteza, queé uma das principais dificuldades encontradas por mulheres que sobrevivem ao câncer de mama e seus cuidadores ${ }^{34}$. Além desta, outra importante causa de sofrimento que se destacou nos relatos foram as alterações na sexualidade e identidade das pacientes.

\section{Colaboradores}

JSC Tavares conduziu a pesquisa que derivou no artigo, redigiu a maior parte do conteúdo do artigo enviado e LAB Trad orientou o desenvolvimento da pesquisa que derivou no artigo, participou da redação e concepção geral do artigo e reescreveu trechos da versão final apresentada.

Agradecimentos

Agradecemos ao CNPQ pelo apoio financeiro a esta pesquisa; às famílias participantes, à direção, profissionais e voluntárias do GAM M A do Hospital Aristides M altez (HAM ), a João M arcos de Oliveira pela revisão enormalização do texto. 


\section{Referências}

1. Instituto Nacional do Câncer. Estimativa 2006: Incidência de câncer no Brasil. Rio de Janeiro: INCA 2005.

2. Brasil. M inistério da Saúde. Controle do Câncer de Mama: Documento de Consenso. Rev Bras Cancerol 2004; 50(2):77-90

3. Alves PC, Rabelo MC. Significação e metáforas: aspectos situacionais no discurso da enfermidade. In: Pitta AM R, organizadora. Saúde e comunicação. São Paulo: Hucitec; 1995. p. 217-235.

4. Bromberg MHPF. Cuidados paliativos para o paciente com câncer: uma proposta integrativa para equipe, pacientes e família. In: Carvalho M M M J, organizadora. Psico-oncologia no Brasil: resgatando o viver. São Paulo: Summus; 1998. p. 186-231.

5. Bastos ACS, Trad LAB. A família enquanto contexto de desenvolvimento humano: implicações para a investigação em saúde. Cien Saude Colet 1998; 3(1):106-115.

6. M CDaniel SH, Hepworth J, Doherty WJ. Os desafios da doença crônica. In: M CDaniel SH, Hepworth J, Doherty WJ. Terapia familiar médica. Porto Alegre: Artes Médicas; 1994. p. 179-204.

7. Queiroz E, Gimenes M GG. As diferentes fases de enfrentamento durante o primeiro ano após a mastectomia. In: Gimenes M G, organizadora. A mu Iher e o câncer. São Paulo: Psy II; 1997. p. 173-195.

8. Santana ADA. Cuidados paliativos ao doente oncológico terminal em domicílio: representações sociais da família [dissertação]. Salvador (BA): Universidade Federal da Bahia; 2000.

9. Sant'Anna DB. A mulher e o câncer na história. In Gimenes MG, organizadora. A mulher e o câncer. São Paulo: Psy II; 1997. p. 43-70.

10. Tavares JSC, Trad LAB. M etáforas e significados do câncer de mama na perspectiva de cinco famílias afetadas. Cad Saude Publica 2005; 21(2):426-435.

11. Holland JC, Rowland JH, editors. Handbook of Psychooncology: Psychological care of the patient with cancer. New York: Oxford University; 1990.

12. Beltran AG, Barreto SS, Gutiérrez M GR. Cuidando de pacientes que faleceram por câncer de mama: a experiência dos familiares. Rev Bras Cancerol 2000; 46(2):155-162.

13. Bervian PI, Girardon-Perlini NMO. A família (con) vivendo com a mulher/mãe após a mastectomia. Rev Bras Cancerol 2006; 52(2):121-128.

14. Biffi RG. A dinâmica familiar de um grupo de mulhe res com câncer de mama [tese]. Ribeirão Preto (SP): Universidade de São Paulo; 2003.

15. Oliveira FS, Zago M M F. A experiência do laringectomizado e do familiar em lidar com as consequências da radioterapia. Rev Bras Cancerol 2003; 49(1):17-25.

16. Pedrolo FT, Zago M M F. 0 enfrentamento dos familiares à imagem corporal alterada do laringectomizado. Rev Bras Cancerol 2002; 48(1):49-56

17. Dolbeault S, Szporn A, Holland JC. Psycho-oncology: Where have we been? Where are we going? Eur J Cancer 1999; 35(11):1554-1558.
18. Lipp MEN, organizadora. M ecanismos neuropsicofisiológicos do stress: teoria a aplicações clínicas. São Paulo: Casa do Psicólogo; 2003.

19. Bromberg MHP. Ser paciente terminal: a despedida anunciada. In: Berthoud CME, Bromberg MHP F, Coelho M RM. Ensaio sobre formação e rompimentos de vínculos afetivos. Taubaté: Cabral Editora Universitária; 1998. p. 69-95.

20. Dura JR, Kiecolt-Glaser JK. Family, Transitions and Health. In: Cowan PA, Hetherington M, editors. Family transitions. London: Lawrence Earlbaum; 1991.

21. Deitos TFH, Gaspary JFP. Efeitos biopsicossociais e psiconeuroimunológicos do câncer sobre o paciente e familiares. Rev Bras Cancerol 1997; 43(2):117125.

22. Lazarus RS, Folkman S. Stress, appraisal and coping New York: Springer Publishing; 1984.

23. Antoniazzi AS, Dell'Aglio D, Bandeira D. 0 conceito de Coping: uma revisão teórica. Estud. Psicol. 1998; 3(2):273-294.

24. Glanz K, Lewis F, Rimer B, editors. Health behavior and health education: theory, research, and practice. San Francisco: Jossey- Bass Publishers; 1997.

25. Lazarus RS. Toward better research on stress and coping. American Psychologist 2000; 55(6):665-673.

26. Somerfield M R, M cCrae RR. Stress and coping research: methodological challenges, theoretical advances, and clinical applications. American Psychologist 2000; 55(6):620-625.

27. Tavares JSC. 0 processo de enfrentamento do câncer em famílias de mulheres com câncer de mama [dissertação]. Salvador: U niversidade Federal da Bahia; 2002.

28. Biffi RG. 0 suporte social do parceiro sexual na reabilitação da mulher com câncer de mama [dissertação]. Ribeirão Preto (SP): Universidade de São Paulo Ribeirão Preto; 1997.

29. Gimenes M G. A pesquisa do enfrentamento na prática psico-oncológica. In: Carvalho MMMJ, organizadora. Psico-oncologia no Brasil: resgatando o viver. São Paulo: Summus; 1998. p. 232-246.

30. Gimenes M G. A teoria do enfrentamento e suas implicações para sucessos e insucessos em Psiconcologia. In: Gimenes MG, organizadora. A mulher e 0 câncer. São Paulo: Psy II; 1997. p. 111-147.

31. Cerveny C. A família como modelo: desconstruindo a patologia. São Paulo: Psy II; 1994.

32. Auge M. Os domínios do parentesco. Lisboa: Edições 70; 2003

33. N ascimento-Schulze CM, organizadora. Dimensões da dor no câncer: reflexões sobre o cuidado interdisciplinar e um novo paradigma de saúde. São Paulo: Robe; 1997

34. Nelson JP. Struggling to gain meaning: living with the uncertainty of breast cancer. Advances in nursing science 1996;18(3):59-76.

Artigo apresentado em 08/01/2008

Aprovado em 25/08/2008

Versão final apresentada em 21/11/2008 